\title{
Perfeccionamiento de las vías procesales para la tutela judicial efectiva del derecho a un medio ambiente sano $y$ equilibrado en Cuba
}

\section{Improvement of the Procedural Roads for it Guides her Judicial Effective of the Right to a Healthy and Balanced Environment in Cuba}

MS.c Emilio Castillo Torres * https://orcid.org/0000-0003-2107-137X

Lic. Juan Carlos Mendoza Pérez ** https://orcid.org/0000-0003-3197-9605

MS.c Carmen Sugranyes Ramos *** https://orcid.org/0000-0001-8441-5235

http://dx.doi.org/10.21503/lex.v18i26.2185

* Profesor Auxiliar de Derecho Constitucional y Derechos Humanos en el Departamento de Derecho de la Universidad de Guantánamo, Cuba.

Correo electrónico: sergioemilio@nauta.cu

** Profesor Auxiliar de Derecho Administrativo I, II y Derecho de Obligaciones en el Departamento de Derecho de la Universidad de Guantánamo, Cuba.

Correo electrónico: jcperez@cug.co.cu.

*** Profesora Asistente de Derecho Civil Parte General, Derecho de Familia y Derecho Procesal Civil, en el Departamento de Derecho de la Universidad de Guantánamo, Cuba.

Correo electrónico: carmita@fpgt.fgr.gob.cu.

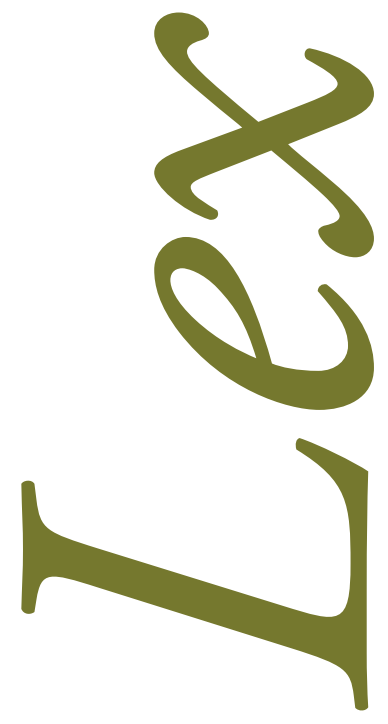




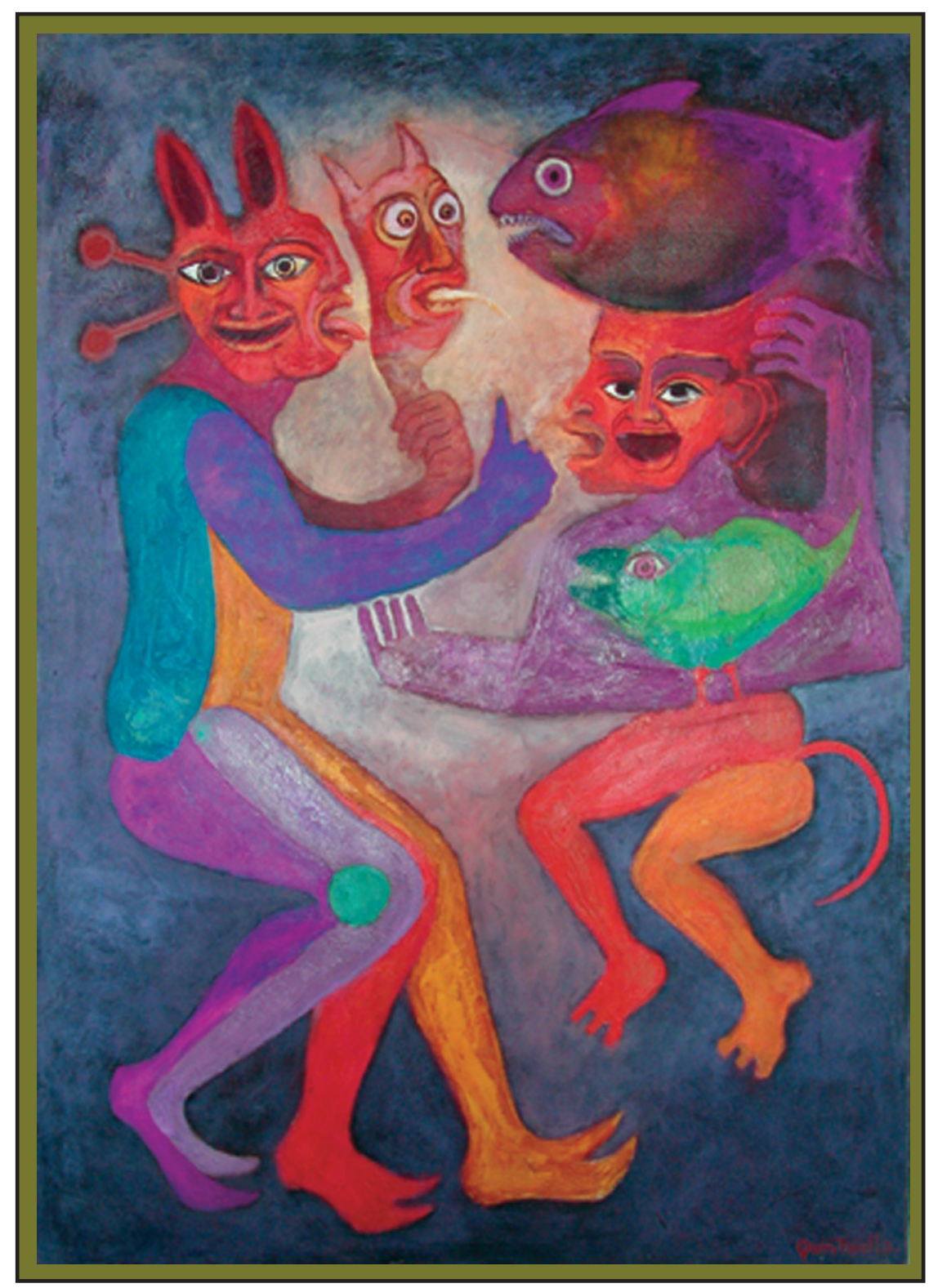

Pases mágicos. Mixto, 1978. Artista plástico peruano, Alberto Quintanilla (Cusco, 1934). 


\section{RESUMEN}

La presente investigación pretende proponer desde una perspectiva histórica, doctrinal y normativa el perfeccionamiento de los presupuestos teóricos y normativos para la implementación de un sistema de mecanismo encaminados la tutela efectiva del derecho a un ambiente sano y ecológicamente equilibrado en el ordenamiento jurídico cubano. Para cumplir la pretensión del mismo se utilizaron los siguientes métodos: análisis-síntesis, la inducción-deducción, teórico-jurídico, jurídico-comparativo y exegético. Método empírico: análisis de contenido.

Palabras clave: medio ambiente, vías procesales, tutela judicial, presupuestos teóricos y normativos.

\section{ABSTRACT}

The present investigation seeks to propose from a historical, doctrinal and normative perspective the improvement of the theoretical and normative budgets for the implementation of a guided mechanism system the it guides effective of the right to a healthy atmosphere and ecologically balanced in the Cuban juridical classification. To complete the pretense of the same one the following methods they were used: analysis-synthesis, the induction-deduction, theoretical-juridical, juridical-comparative and exegetic. Empiric method: content analysis.

Key words: environment, procedural roads, it guides judicial, theoretical and normative budgets. 


\section{INTRODUCCIÓN}

Los problemas ambientales son una realidad difícil de negar hoy en día. Es tan común hablar de calentamiento global y de los altos niveles de contaminación provocada en diversas zonas del planeta, por los habitantes de estas últimas, que no resulta sorprendente que se emprenda la búsqueda de posibles soluciones para esta realidad, desde diversos ámbitos, incluso a partir de modificaciones a los diversos ordenamientos jurídicos existentes; creándose con este fin, mecanismos que permitan a las personas actuar, de tal forma que pongan en funcionamiento los órganos de la rama judicial, para que mediante decisiones contenidas en providencias adoptadas por estos, se proteja el "(...) derecho constitucional de todas las personas al disfrute de un ambiente sano, el cual se encuentra consagrado expresamente en el artículo 79 de la Carta Política, clasificado dentro de los Derechos Colectivos y del Ambiente"1.

Por consiguiente, una de las principales preocupaciones en la defensa de los derechos humanos, y entre ellos los derechos de tercera generación, es el acceso a la justicia; es urgente la posibilidad de contar con instrumentos ágiles, con énfasis en lo preventivo, donde las ordenes que dé el juez sean justas, conocidas y efectivas. No basta el acceso a los tribunales: se requiere también el acceso a los mecanismos alternativos ${ }^{2}$.

1. Corte Constitucional, Sala plena de la Corte Constitucional. Expediente T-904. Sentencia SU-067 de 1993. Bogotá, 24 de febrero de 1993. Magistrados Ponentes: Fabio Morón Díaz y Ciro Angarita Barón.

2. Beatriz Londoño Toro, "Algunas reflexiones sobre la exigibilidad de los derechos colectivos y del ambiente", en Perspectivas del Derecho Ambiental en Colombia, (Bogotá: Editorial Universidad del Rosario, 2006),62. Vid. María Luisa Carmona Lara, Derechos en relación con el medio ambiente. Instituto de investigaciones Jurídicas. (México: 2000. UNAM). Disponible en internet: http:// www.bibliojuridica.org/libros/libro.htm?l=66. Consultado en fecha 29 de marzo de 2019. Danelia Cutié Mustelier, "El sistema de garantías de los Derechos Humanos en Cuba", (Tesis presentada en opción del Grado Científico de Doctor en Ciencias Jurídicas, Santiago de Cuba, 1999). Lidia María Garrido Cordovera, "La Preservación del Medio ambiente en la Constitución Nacional: La Protección y el Daño Ambiental" en G. J. Bidart Campos, y H. R. Sandler, Estudios sobre la Reforma Constitucional de 1994 (Buenos Aires: Ediciones Depalma 1995), 127. Marco Antonio Muñoz Guzmán, El medio ambiente sano como derecho humano. Disponible en Internet: http://www.scjn.gob.mx/Reforma/Foro/archivos/2743. Consultado en fecha 26 de abril de 2019.

Martha Prieto Valdés, "Garantías y defensa de los derechos fundamentales de la ciudadanía cubana”, en El otro Derecho, ILSA, Vol. 6, No. 2, 1994, Bogotá, pp. 113-122. Jesús Rafael Vallenas Gaona. El derecho a un ambiente sano y ecológicamente equilibrado. Disponible en Internet: http:// www.uv.es/ ripj/11vall2.htm. Consultado en fecha 30 de abril de 2020. 
El Derecho a un Ambiente Sano y Ecológicamente Equilibrado es un derecho de tercera generación o de solidaridad, que en su aspecto subjetivo está concebido como parte del ejercicio colectivo o difuso, posterior a los Pactos Internacionales de Derechos Humanos (aspecto cronológico y formal) y es un derecho orientado a la cooperación y responsabilidad de la comunidad internacional, así como de la estructuración de un nuevo orden económico (aspecto estructural). Siendo manifestado su contenido esencial, a través de dos dimensiones que lo conforman: El derecho a preservar la vida individual en un entorno adecuado y el derecho de la especie a subsistir en las generaciones futuras en un entorno adecuado.

De ahí que, el reconocimiento constitucional expreso del Derecho a un Ambiente Sano y Ecológicamente Equilibrado comenzó a evidenciarse gradualmente a partir de la década de los setenta, figurando en la vanguardia de tal iniciativa el área geográfica latinoamericana. Sin embargo, hasta el momento es evidente la carencia en la doctrina científica y jurisprudencial de un desarrollo teórico en cuanto a mecanismos para la tutela judicial efectiva de este derecho, exigiéndose su necesaria e imprescindible construcción teórica con el propósito de dimensionar correctamente su protección para el disfrute pleno y efectivo del mismo ${ }^{3}$.

Y ello ocurre porque la preocupación por el problema ambiental es uno de los grandes temas en la vida política y social de cualquier país en la actualidad, convirtiéndolo en un paradigma de obligatoria inclusión en la acción de los Estados, y por tanto ya no se discute la necesidad de su inclusión en las constituciones, sin embargo, para llegar hasta aquí se ha debido recorrer un largo camino, durante el cual quizás entre los desafíos teóricos más relevantes que ha debido abordar el derecho como ciencia, es tratar de dar respuesta a las siguientes interrogantes: ¿ Es el derecho a vivir en un ambiente sano y equilibrado un derecho humano que tiene reconocimiento constitucional en todos los ordenamientos jurídicos? y ¿Existe en la actualidad un adecuada tutela jurídica de este derecho, incluida nuestra Constitución y nuestro ordenamiento jurídico? De ahí que sean estas las dos principales interrogantes que en el orden problémico se propone dar respuesta en esta investigación.

En cuanto a la primera interrogante, cabe señalar que a inicios de la década de los sesenta del siglo pasado se produce un proceso paulatino de reconocimiento del derecho a un ambiente sano, que en su inicios se manifiesta en una toma de conciencia general de su necesidad, demostrándose ello en la realización de importantes congresos internacionales sobre el tema de los cuales se desprendieron numerosos instrumentos no vinculantes, muchos de cuyos principios y normas fueron incluidas posteriormente en las distintas normativas ambientales nacionales, ya de obligatorio cumplimiento, incluso

3 La constitucionalización del derecho es uno de los grandes fenómenos que se producen en el mundo jurídico contemporáneo, abarcando en la vida diaria tanto a los operadores del derecho como a los académicos todo lo cual da cuenta de la presencia constitucional en las diversas ramas jurídicas. En tal sentido el derecho ambiental no ha escapado a este fenómeno, ubicándose hoy en el nivel más alto dentro de los ordenamientos jurídicos. Dicha constitucionalización se ha llevado a cabo ya sea consagrando como deber de los Estados el cuidado del ambiente o consagrando un derecho de los ciudadanos con relación al ambiente e inclusive ambas a la vez. 
un número importante de Constituciones las comienzan a consagrar como un derecho fundamental. V.gr.: Entre las cartas magnas pioneras en reconocer este derecho se encuentran las Constituciones de España de 1978; Portugal de 1976; Panamá de 1972; Cuba de 1976; Chile de 1980; Brasil de 1988, entre otras ${ }^{4}$.

Con independencia de lo antes expuesto, muchos autores consultados plantean que si bien el tema del reconocimiento del derecho a un ambiente sano goza de amplio consenso a nivel mundial aún dicho proceso no está del todo concluido y en algunos países por ejemplo no tienen aún una consagración constitucional. Esta situación se debe tal vez entre otras razones a que la preocupación por el ambiente es relativamente reciente, de ahí que estudiosos del tema hace ya algún tiempo insisten en la necesidad de que además de consagrarse como un derecho humano tenga reconocimiento formal, tanto en el ámbito internacional ${ }^{5}$ como en el nacional ${ }^{6}$.

4. En el derecho foráneo puede notarse que ya muchos países han reconocido el derecho fundamental al ambiente, aun cuando en muchos casos no se trata de un reconocimiento directo en la Constitución, sino de un desarrollo jurisprudencial que construye esta protección constitucional -como en Italia-; o sea, se reconoce el derecho al ambiente a partir de otros derechos constitucionales ya establecidos en el texto, lo que le deja un simple carácter subsidiario. La Constitución Política de la República Federal de Alemania hasta 1994 tampoco reconocía directamente un derecho fundamental al ambiente; en esa fecha, mediante una enmienda constitucional basada en la jurisprudencia, se estableció el deber del estado de proteger las condiciones naturales indispensables para la vida como parte de su responsabilidad con las generaciones futuras. En Europa destaca, especialmente, el reconocimiento constitucional al ambiente que se hace en las Constituciones de España 1978 y Portugal de 1976, en esta última se estipula el deber del Estado de proteger los derechos fundamentales. Establece que es un requisito para la protección de la herencia cultural de los portugueses defender la naturaleza y el ambiente, así como la preservación de los recursos naturales.

5. Arista internacional María Luisa Carmona Lara, Derechos en relación con el medio ambiente. Instituto de investigaciones Jurídicas, (México: UNAM. 2000). Disponible en internet: http:// www.bibliojuridica.org/libros/libro.htm?l=66; Miguel Carbonell y Rubén Sánchez Gil. Que es la Constitucionalización del Derecho. Disponible en

https://www.google.com.cu/search?ei=qIFLXOLVIfGiggfVl5aoBg\&q=constitucionalizacion+del+derecho+pdf\&oq=constitucionalización+del+derecho+pdf\&gs_l=psy-ab; Benito De Castro Cid, Los derechos económicos, sociales y culturales: análisis a la luz de la teoría general de los derechos humanos, Universidad de León, (España Secretariado de Publicaciones, León, 1993). Lidia María Garrido Cordovera, "La Preservación del Medio ambiente en la Constitución Nacional: La Protección y el Daño Ambiental” en G. J. Bidart Campos y H. R. Sandler Estudios sobre la Reforma Constitucional de 1994 (Buenos Aires: Ediciones Depalma, 1995), 127; Demetrio Loperena Roara, Los derechos al Medio Ambiente adecuado y a su protección. Biblioteca Virtual. Universidad de País Vasco; Ramón Martín Mateo, Manual de Derecho Ambiental. Segunda Edición Cerrada del 30 de abril de 1998. (Madrid: Editorial TRIVIUM). E. Moreno Trujillo, La protección jurídico-privada del medio ambiente y la responsabilidad por su deterioro, (Barcelona: J. M. Bosh Editor, 1991); Marco Antonio Muñoz Guzmán, El medio ambiente sano como derecho humano. Disponible en Internet: http:// www.scjn.gob.mx/Reforma/Foro/archivos/2743.

6. En la arista nacional: Danelia Cutié Mustelier. "El sistema de garantías de los Derechos Humanos en Cuba”, (Tesis presentada en opción del Grado Científico de Doctor en Ciencias Jurídicas, Santiago de Cuba, 1999); Leonel Caraballo Maqueira. "El pensamiento ambiental cubano" Multimedia Derecho Ambiental Cubano. (La Habana 2006); Victorio Di Cagno, "La Protección del Medio Ambiente en Cuba". Edición provisional para la V Conferencia Internacional sobre Medio Ambiente y Desarrollo. (La Habana: Editorial de Ciencias Sociales, 2005); Ivette Rancol Borrero "La Protección Jurídica Penal del Medio Ambiente en Cuba, Trabajo de diploma presentado en opción al título de licenciada en Derecho", (Universidad de Guantánamo: 2017). MS.C Sergio Emilio Castillo Torres. "Reconocimiento y Garantías del Derecho a un Ambiente Sano y Ecológicamente Equilibrado en Cuba", (Tesis presentada en opción al título académico 
En los años más recientes y partiendo de la concientización que sobre el tema se ha producido entre un número creciente de ciudadanos, incluidos a los que ostentan el poder político, se ha asistido en el ámbito constitucional a una nueva tendencia que algunos autores han denominado como la constitucionalización del medio ambiente, la que se encuentra íntimamente ligada a la creación de nuevos derechos colectivos y a su consagración como un nuevo derecho humano fundamental ${ }^{7}$.

En la segunda interrogante no existe una respuesta igualmente satisfactoria, pues los mecanismos procesales para la tutela a este derecho desafortunadamente no se han desarrollado a la par de su reconocimiento, y en consecuencia no hay una solución homogénea al respecto en el ámbito procesal, empleándose, salvo excepciones, en el mejor de los casos las vías tradicionales que ofrece el derecho procesal a través de las cuales se procura lograr el acceso a la tutela efectiva cuando de alguna forma considera vulnerado el derecho a un ambiente sano y ecológicamente equilibrado. Por lo que es importante decir que no son en la actualidad las vías de tutela empleadas las más efectivas tratándose como se sabe, de un derecho con características especiales que le distingue de las anteriores generaciones de derechos, y que por tanto requiere igualmente de mecanismos no tradicionales de protección so pena de no tornarse real su disfrute y garantía. Cuestión por otra parte, imprescindible para el pleno ejercicio de la vida de todo ser humano.

Dicho lo anterior entonces se está de acuerdo en que ningún tema ha suscitado tanto interés y comprometimiento mundial como ha sido y es el relacionado con los problemas del ambiente, de ahí que con este propósito la lucha por el reconocimiento del ambiente como un derecho humano tenga una historia de unos 25 años, periodo en el que la doctrina especializada ha venido propugnando su reconocimiento en los ámbitos nacional e internacional ${ }^{8}$, lo cual ha encontrado un escollo proveniente, prin-

de máster, Universidad de Oriente, 2006). Entre otros.

7. Constituyendo paradigmas en este sentido la Constitución de Colombia (1991), la Constitución República Bolivariana de Venezuela (1999), la Constitución de la República del Ecuador (2008) y la Constitución del Estado Plurinacional de Bolivia (2009), constituciones que por supuesto serán objeto de nuestra atención más adelante.

8. La Declaración Universal de los Derechos Humanos, de 1948, establece claramente que "toda persona tiene el derecho a un nivel adecuado de vida que le asegure, así como a su familia, la salud y el bienestar". El Pacto Internacional de Derechos Civiles y Políticos, de 1966, establece, directamente, el carácter del ambiente como un requisito indispensable para el adecuado desarrollo de la persona. La Declaración de las Naciones Unidas sobre el Medio Ambiente Humano, de Estocolmo-1972, establece que es un derecho del hombre gozar de las "condiciones de vida satisfactorias en un ambiente cuya calidad le permita vivir con dignidad y bienestar". Como contrapartida a este derecho, la misma Declaración reconoce el "deber solemne de proteger y mejorar el medio ambiente para las generaciones presentes y futuras". En la Reunión Mundial de Limoges, de 1990, se recomendó que el derecho del hombre al ambiente fuera reconocido a nivel nacional e internacional y que los estados tengan el deber de garantizarlo. La Carta de Derechos Ambientales y Obligaciones de Individuos, Grupos y Organizaciones, adoptada en Ginebra en 1991, se manifiesta en el mismo sentido: “Todos los seres humanos tienen el derecho fundamental a un ambiente adecuado para su salud y bienestar y la responsabilidad de protegerlo para el beneficio de la presente y de futuras generaciones". La Cumbre de Río de Janeiro, de 1992, consolidó la evolución de este derecho al señalar que todos los seres humanos tienen derecho a una vida saludable y productiva en armonía con la naturaleza. En la Declaración de Vizcaya (Bilbao; Seminario Internacional sobre Derecho al Ambiente; 1999) se deja clara la condición de derecho humano que tiene el ambiente, indicándose que se relaciona con el respeto 
cipalmente, de la dificultad de definir el carácter de tal derecho. La dificultad para el reconocimiento de un derecho constitucional al ambiente radica, especialmente, en la confusión entre el reconocimiento del derecho y la necesidad de su protección. En efecto, una cosa es reconocer el derecho y otra proveer para su efectiva realización y protección.

Partiendo de las problemáticas anteriormente expuestas se pretende con esta investigación vincular la dimensión jurídica que ha adquirido tal contexto y al estudio del tema de las garantías y el acceso de los ciudadanos a la tutela judicial efectiva en caso de la vulneración del mismo. Siendo una de las variantes de mayor aproximación, identificar los obstáculos que impiden o limitan la tutela judicial efectiva en Cuba, como parte de todo un movimiento legislativo que se ha venido desarrollando desde concepciones actualizadas por la propia internacionalización del fenómeno.

Con esta finalidad se valora en primer lugar, si el texto constitucional en particular y el ordenamiento jurídico en general ofrecen reconocimiento explícito al derecho a un ambiente sano y ecológicamente equilibrado. También las posibles vías o acciones legales con la que cuenta el ciudadano para prevenir un daño ambiental irreparable, lograr el acceso a la vía jurisdiccional cuando se haya consumado una violación de este tipo para su perfeccionamiento y actualización.

Motivados por la actualidad del tema y el poco tratamiento dado en el ámbito doctrinal y legal, así como la necesidad de perfeccionar las vías procesales dirigidas a la tutela judicial efectiva del derecho a un ambiente sano y equilibrado en el país se traza la presente cuyo objeto de estudio es el medio ambiente, con un campo de acción que radica en el perfeccionamiento de las vías procesales para su tutela judicial efectiva en Cuba.

\section{REFLEXIONES EN TORNO A LOS MECANISMOS DE GARANTÍAS DE LOS DERECHOS}

En la doctrina constitucional es generalmente aceptado que el problema de los derechos humanos no consiste en determinar su fundamento, ni radica en su reconocimiento o formulación jurídica, sino que el principal problema que afrontan los derechos humanos es el concerniente a su eficacia y realización y, consecuentemente, al sistema de garantías que constitucional o legalmente se haya previsto para alcanzar su efectividad. De ésta manera, se ha hecho supeditar la vigencia de los derechos fundamentales a la vigencia de sus garantías; e incluso, se ha predicado su inexistencia jurídica cuando no se les ha dotado de garantía alguna.

Pero si bien la existencia de un adecuado y eficaz sistema de protección y aseguramiento de los derechos humanos es imprescindible para la eficacia de estos, no se puede esperar que resuelva por

a la dignidad de todo ser humano; se ratifica el derecho a un ambiente sano y equilibrado y la responsabilidad pública y de organizaciones internacionales de protegerlo, velando por el uso racional de los recursos naturales y el impulso de modelos de producción y uso que conduzcan a un desarrollo sustentable. 
completo todas las dificultades de "eficacia y realización" que puedan presentar, sobre todo si se desea que la solución sea verdaderamente eficaz. Muy por el contrario, un sistema de garantías a los derechos humanos se mostrará ineficaz si para su aplicación e incluso si para su formulación jurídica, no se conoce convenientemente lo que es objeto de aseguramiento: el contenido del derecho constitucionalmente reconocido. No se puede formular ni aplicar un sistema de garantías de derechos fundamentales si antes no se conoce cuales facultades y atribuciones y con qué alcance dispensa un determinado derecho fundamental a su titular. Es por ello que en el capítulo precedente se ha realizado un análisis del derecho objeto de estudio. Sin embargo, es conveniente, adentrarse, aunque sea brevemente en algunas consideraciones doctrinales en torno al tema de las garantías.

Las garantías a los Derechos Humanos han sido definidas como el conjunto de instrumentos jurídicos de aseguramiento de los derechos y libertades y por ende, del valor normativo de la Constitución. El término garantía se encuentra vinculado en su origen a las primeras declaraciones de derechos en los textos constitucionales, considerándose en esa época que los derechos estaban garantizados con el simple establecimiento o su consagración en la carta fundamental, incluso se ha considerado que la primera garantía del derecho es su reconocimiento, sin embargo la sola consagración constitucional de los derechos fundamentales no evita que sus titulares, en ocasión de ejercerlos, pueden apreciarlos disminuidos, amenazados o vulnerados, bien por el Estado o por los particulares, por lo tanto debe ir este reconocimiento acompañado de garantías que asegurasen con eficacia el libre ejercicio de tales derechos.

La doctrina se ha encargado de establecer que derecho y garantía son dos categorías que guardan una estrecha relación, aun cuando sus significados sean diferentes, siendo reservada a la garantía un lugar de significativa importancia para la estabilidad de los ordenamientos jurídicos en cuanto a los derechos que estos pregonan, tan es así que se ha dicho con razón que los derechos valen lo que valen sus garantías. De esta forma las garantías de los derechos humanos pasan a convertirse en el complemento imprescindible para hacer posible el tránsito que media desde el reconocimiento de los derechos hasta su real eficacia jurídica en las relaciones humanas. Es decir, que la efectividad de los derechos depende tanto de su reconocimiento constitucional como de la existencia de mecanismos adecuados, prácticos y expeditos para prevenir sus violaciones y reaccionar contra ellas, unido a la necesaria condicionalidad material para su pleno disfrute.

Numerosas han sido las vías implementadas por la doctrina dirigidas a garantizar que los ciudadanos disfruten de manera real y efectiva sus derechos constitucionalmente reconocidos, y hoy por ejemplo se acepta que los derechos fundamentales tienen eficacia directa, esto es, que vinculan a los poderes públicos y son inmediatamente tutelables por los tribunales sin necesidad de leyes interpuestas, la regulación de los derechos y libertades incluye mandatos al legislador, garantías judiciales, etc. Debido a lo anterior también han sido diversas las clasificaciones señaladas por la doctrina para enmarcar los mecanismos de protección empleados por los diferentes sistemas de derecho, en este sentido seguimos la clasificación 
propuesta por la profesora Cutie Mustelier ${ }^{9}$, Compartida también por tratadistas de reconocido prestigio como Fix-Zamudio ${ }^{10}$, quienes distinguen tres tipos esenciales de garantías: las jurisdiccionales, las no jurisdiccionales y las normativas o abstractas.

Las Garantías Jurisdiccionales, son aquellas que dan la posibilidad de demandar ante órganos de este género (tribunales) la preservación o el restablecimiento de los Derechos Humanos. Se les conoce con el nombre de instrumentos reactivos o garantías concretas, pues se ofrecen a los ciudadanos para que, en caso concreto en que se produzca la vulneración de un derecho, puedan acudir a ellas y obtener la debida protección. Dentro de las garantías jurisdiccionales cabe destacar:

a) Garantías Jurisdiccionales Generales u Ordinarias, que Fix Zamudio denominó remedios procesales indirectos, refiriéndose a los procedimientos ordinarios (civil, penal, laboral y la justicia administrativa) a través de las cuales se protegen los derechos de carácter ordinario, pero que en forma refleja pueden utilizarse para la tutela de los Derechos Humanos.

b) Garantías Jurisdiccionales Específicas: Son aquellos remedios procesales creados exclusivamente para el muy específico fin de proteger los derechos humanos, son, por tanto, procesos de cognición limitada. Se distinguen por brindar de forma directa, rápida y eficaz tutela a los derechos humanos reconocidos por el ordenamiento constitucional, es decir, el modo de proceder debe caracterizarse por la inmediatez, por la máxima urgencia y abreviación en la tramitación y solución, compatibles con un conocimiento adecuado del problema a dilucidar, siendo los efectos del fallo protector esencialmente reparador, es decir, no solo requiere de la sanción sino que dispone la restitución al afectado en el goce de sus derechos.

c) Ordinarias, cuando se trata de un procedimiento específico para la defensa de los derechos humanos ante los propios órganos judiciales ordinarios Ejemplo. El Habeas Corpus.

d) Extraordinarias, cuando se trata de un procedimiento específico para la defensa de los derechos humanos ante órganos jurisdiccionales especiales o especializados, como es el caso de los recursos o procedimientos establecidos en algunos países ante los Tribunales Constitucionales.

Con independencia de lo antes expuesto, es importante decir que un segundo escalón dentro de la diversidad de mecanismos de protección de los derechos humanos lo constituyen las garantías no Jurisdiccionales que no pueden considerarse como instrumentos procesales en sentido estricto, pues se trata de órganos o instituciones que se han establecido con la función esencial de tutelar o fiscalizar los derechos humanos. En este caso se encuentra el Ombudsman de origen escandinavo que ha sido asi-

9. Danelia Cutié Mustelier. "El sistema de garantías de los Derechos Humanos en Cuba”, (Tesis presentada en opción del Grado Científico de Doctor en Ciencias Jurídicas, Santiago de Cuba, 1999).

10. Héctor Fix-Zamudio. La garantía jurisdiccional de la Constitución mexicana. Ensayo de una estructuración procesal del amparo. (México: UNAM, Porrúa, Instituto de Investigaciones Jurídicas, IMDPC, 2015), 191. 
milado por varios ordenamientos contemporáneos donde ha recibido distintas denominaciones como la de defensor del pueblo, en el caso España y Venezuela. Aunque ha ido evolucionando, la misión fundamental de esta institución ha sido la de supervisar la actividad de los funcionarios públicos para defender a los particulares contra el proceder ilegal de la administración pública.

También se sitúa dentro de estas garantías al Ministerio Fiscal, que tiene atribuida la función de ejercitar la acción penal en representación del Estado; es un órgano de control y fiscalización de la legalidad y en tal sentido puede, promover la acción de la justicia en defensa de los derechos de los ciudadanos. Es evidente que esta institución carece de naturaleza procesal y aunque posee sus propias peculiaridades que la distinguen del Ombudsman, en materia de protección de los derechos humanos tiene funciones similares en cuanto a la recepción, atención, tramitación, investigación y solución de las quejas planteadas por la población, así como que sus decisiones carecen de fuerza vinculante adoptando la forma de proposiciones, recomendaciones, o sugerencias.

El tercer grupo de mecanismos protectores de los derechos humanos lo conforman las llamadas Garantías Normativas o Abstractas, cuyo objeto es evitar que la actividad de los órganos estatales fundamentalmente el legislativo y el ejecutivo puedan implicar un desconocimiento o vulneración de los derechos humanos. En este grupo encontramos la Reserva de Ley, el contenido esencial de los derechos, los límites intrínsecos en la regulación constitucional y la eficacia directa. Luego de a ver incursionado en el análisis del reconocimiento y las garantías del derecho a aun ambiente ecológicamente y equilibrado se puede decir que sobre la naturaleza y esencia del derecho a un ambiente sano y ecológicamente equilibrado, que se está frente un derecho con características especiales que lo distinguen del resto de las anteriores generaciones de derechos e incluso presenta significativa connotación aún dentro de aquellos derechos que clasifican dentro de los llamados de solidaridad o de la tercera generación, por tanto se coincide plenamente con un gran número de autores que proclaman la necesidad de implementar garantías especiales para un derecho que de alguna forma también lo es, sobre todo por la esencia del derecho tutelado, con implicaciones no solo para la vida y supervivencia de su titular supuestamente afectado, sino para a la supervivencia de las futuras generaciones de sus descendientes, y mucho más dramático aún, la supervivencia de todo el planeta con sus numerosas formas de vida.

En este sentido se puede advertir que con las diferencias propias que corresponde a cada país todas las normativas nacionales sobre ambiente contienen una serie de medidas administrativas generales que especifican los órganos estatales o locales encargados de su aplicación y control, regulan el procedimiento para la obtención de licencias para desarrollar actividades contaminantes controladas, otras establecen procedimientos de revisión de resoluciones administrativas para la obtención de licencias y para la comprobación de actividades y en muchas ocasiones, insertan un procedimiento sancionador para los casos de incumplimiento. Sin embargo, no existen mecanismos eficaces para el acceso del ciudadano a la tutela judicial efectiva cuando le ha sido vulnerado el derecho a un ambiente sano y ecológicamente equilibrado. 
En tal caso ocurre que ante la frecuente ausencia de mecanismos adecuados los sujetos se ven obligados a aprovechar las vías procesales ordinarias y tratar en ellas de hacer valer sus pretensiones ambientales, sin embargo, estas por las razones ya señaladas y otras que explicaremos a lo largo del trabajo, no alcanzan el nivel de efectividad adecuado o requerido. Dicho de otro modo, se trata de que el nivel de consenso alcanzado en el reconocimiento del derecho a un ambiente sano por casi todos no ha ido acompañado de igual modo en la implementación de los mecanismos para su efectiva garantía, entendidas como las vías procesales para lograr una tutela judicial efectiva por parte del ciudadano, sin cuya garantía definitivamente no existirá el disfrute efectivo del derecho, aunque se haga formalmente su reconocimiento por todos.

Como se ha reiterado el tema de las garantías al derecho a un ambiente sano se complica un tanto partiendo de la singularidad del mismo que le distingue de los restantes, necesitando de determinados presupuestos en el orden procesal para que sea realmente efectiva su tutela en caso de su vulneración, y que a consideración del autor desde la perspectiva del derecho comparado no existe una solución doctrinal homogénea al respecto y si diferentes vías a través de las cuales se logra o pretende lograr el acceso a la tutela efectiva del ciudadano esencialmente a partir del acomodo de las instituciones tradicionales del derecho, que como se verá están lejos de ofrecer la protección adecuada, incluso las más de las veces inaccesibles o desconocidas por los ciudadanos.

Por su parte el autor Bobbio, refiere que el problema de los derechos fundamentales ya no consiste en su reconocimiento solemne sino en la posibilidad de tornarlos realmente efectivos. Por tanto, el reconocimiento del derecho a un ambiente sano y equilibrado, y el desarrollo de la legislación de protección del ambiente, requieren de medios o instrumentos a través de los cuales se asegure el efectivo cumplimiento de esas normas por parte del Estado y de los particulares ${ }^{11}$.

De esta manera, la persona perjudicada puede reclamar o demandar la defensa o conservación de su derecho ante el poder ejecutivo (por la vía administrativa), y/o ante el poder judicial (por la vía jurisdiccional).

Este asunto de las garantías cobra importancia a partir de que el acceso a la justicia en defensa de un Ambiente Sano es una de las formas a través de las cuales los ciudadanos decididamente participan en el control del cumplimiento de las normas ambientales. De ahí que sea prudente entonces realizar un análisis en el derecho patrio del proceso de constitucionalización de este derecho a partir de su expresión en las cartas mangas de 1976 y del 2019, así como los mecanismos de garantías que se utilizan en el país.

11. Norberto Bobbio, Studi per una Teoria Generale del Diritto. (Torino: Giappichelli, 1970). 


\section{CONSTITUCIONALIZACIÓN DEL DERECHO A UN AMBIENTE SANO Y EQUILIBRADO EN LA CONSTITUCIÓN DE LA REPÚBLICA DE 1976 Y DEL 2019}

Luego de incursionar en un conjunto de consideraciones doctrinales en torno a reconocimiento y las garantías al derecho a un ambiente sano y ecológicamente equilibrado y su realización práctica actual en el derecho constitucional comparado, pasemos a ver como se reconoce y garantiza este derecho en el ordenamiento jurídico cubano. Debemos decir que la primera referencia al tema ambiental desde el punto de vista constitucional se realiza en la Constitución de 1976 cuando en su artículo 27 establece el deber del Estado, sus órganos y los ciudadanos de velar por el uso racional de los recursos naturales.

La Constitución socialista de 1976, elevó por primera vez en nuestro país a rango constitucional el deber de todas las personas naturales y jurídicas de proteger la naturaleza al disponer en otra parte del artículo 27 que "para asegurar el bienestar de los ciudadanos, el Estado y la sociedad protegen la naturaleza. Incumbe a los órganos competentes y además a cada ciudadano velar porque sean mantenidas limpias las aguas, la atmósfera, y que se proteja el suelo, la flora y la fauna”. Es evidente el sentido antropocentrista del artículo, la protección de la naturaleza estaba en función del bienestar del hombre, lo cual está presente en todo el ordenamiento jurídico ambiental cubano.

En 1992 ante la necesidad de adaptar la norma constitucional a la realidad, del momento se lleva a cabo un grupo de modificaciones a la Constitución de 1976, coincidentemente en ese propio año se había producido la Cumbre de Rio, en la cual se habían aprobado importantes documentos en cuanto a políticas y estrategias dirigidas a la Conservación de la diversidad biológica, sobre la base en primer lugar, de las necesidades y problemas que se enfrentan y ponen en peligro la viabilidad de la vida en la Tierra y a tono con dichos requerimientos el artículo 27 de nuestro texto constitucional quedó redactado de la manera siguiente: "Artículo 27. El Estado protege el medio ambiente y los recursos naturales del país. Reconoce su estrecha vinculación con el desarrollo económico y social sostenible para hacer más racional la vida humana y asegurar la supervivencia, el bienestar y la seguridad de las generaciones actuales y futuras. Corresponde a los órganos competentes aplicar esta política.

Es deber de los ciudadanos contribuir a la protección del agua, la atmosfera, la conservación del suelo, la flora, la fauna y todo el rico potencial de la naturaleza. "Con la modificación del artículo 27 es indudable que se produce por primera vez la idea de constitucionalizar el deber de preservar el ambiente, por otro lado llama nuestra atención el hecho de haber sido enmarcado dicho artículo 27 dentro del capítulo I el cual corresponde a los "Fundamentos políticos, sociales y económicos del Estado", haciéndose con ello evidente a nuestro entender la intención del legislador constitucional de resaltar la significación del bien constitucionalizado.

En el medio jurídico interno las opiniones fueron diversas en cuanto al alcance del artículo 27 de la Constitución de 1976, modificada, al tutelar el derecho a un ambiente sano y ecológicamente 
equilibrado, toda vez que en el mismo literalmente solo queda establecida la co-responsabilidad del Estado y el ciudadano en la protección del ambiente, somos del criterio de que a pesar de la deficiente construcción dogmática a la que se recurre en ese momento, en parte el asunto pudo un tanto salvarse en tanto a partir del análisis exegético en esta podían advertirse los supuestos básicos que dimensionan el contenido esencial del derecho que se pretende reconocer.

En tal caso al analizar detenidamente el artículo 27 de la Constitución modificada de 1976, encontramos, como ya se ha dicho, la existencia de un contenido múltiple pues en primer lugar establece la obligación del Estado y sus instituciones de proteger el ambiente y de velar por el uso racional de los recursos naturales, así como el deber de todos los ciudadanos de conservar el ambiente. En el propio artículo se manejan los elementos a ser reconocidos y protegidos por el estado dada su vinculación con el ambiente entre estos: desarrollo económico social sostenible, vida humana racional, así como: la supervivencia, el bienestar y la seguridad de las generaciones actuales y futuras.

Ahora bien, con la nueva Constitución cubana de 2019, a juicio de los autores se consagra definitivamente el proceso de constitucionalización del derecho a un ambienta sano y equilibrado iniciado con la Constitución de 1976, en tanto, en su artículo 75 declara de manera explícita el derecho que tienen todas las personas al disfrute del mismo. Igualmente se declara que el Estado protege el medio ambiente y los recursos naturales del país. Reconoce su estrecha vinculación con el desarrollo sostenible de la economía y la sociedad para hacer más racional la vida humana y asegurar la supervivencia, el bienestar y la seguridad de las generaciones actuales y futuras.

Uno de los cambios más significativos con relación al texto de 1976 es la ubicación del articulo 75 dentro del Título $\mathrm{V}$ dedicado los Derechos, deberes y garantías, inclusión que implica por parte del Constituyente el reconocimiento de dicho bien jurídico, como un derecho ubicándolo en el mismo rango normativo de otros derechos subjetivos clásicos, tales como la vida, la libertad, la salud y la educación, con lo cual sin dudas ha quedado fijada de manera definitiva nuestra posición, si tenemos en cuenta que una de las problemáticas en la que no hay consenso es precisamente sobre qué tratamiento darle al derecho al ambiente sano, existiendo distintas posiciones, en una amplia gama que va desde el considerarlo un principio programático, hasta aquellos que lo consideran un derecho, y aun dentro de las posiciones que lo consideran un derecho también se encuentran matices que van desde considerarlo un derecho subjetivo (individual o colectivo, fundamental o no), y quienes consideran que la categoría derecho subjetivo no puede ser utilizada para explicarlo. Diversidad que aumenta si se tiene en cuenta que se usan conceptos como derecho subjetivo, derecho colectivo y derecho fundamental, que son conceptos de por sí bastante debatidos y con distintas acepciones.

Otro aspecto que queda bien refrendado dentro de la nueva Constitución es la consideración del ambiente como un bien jurídico colectivo cuyos titulares somos "todas las personas" entendidos como colectividad y no cada uno considerado individualmente. En tal sentido creemos que la intención del legislador constituyente haya sido el no dejar que cada persona que se sienta dañada en su derecho 
ambiental, se defienda sola y como pueda, porque una atomización de la protección relativizaría el reconocimiento del bien jurídico. La protección ambiental sustentada exclusivamente en la existencia de un derecho subjetivo, sería insuficiente si no estuviera apoyada por la capacidad interventora del Estado. Es decir, la defensa del ambiente es básicamente el resultado de la concepción y ejecución de una determinada política diseñada por el Estado. Por ello conforme a la Constitución el destinatario final del deber que nace del artículo 75 es preferentemente el Estado, quedando ello claramente establecido cuando establece que "El Estado protege el medio ambiente y los recursos naturales del país".

$\mathrm{Al}$ analizar detenidamente el artículo 75 de la nueva carta magna aparece, conforme ha sido definido por la doctrina, en su contenido esencial la existencia de un contenido múltiple pues además de consagrar el derecho de la persona al disfrute de este derecho, simultáneamente establece la obligación del Estado y sus instituciones de proteger el ambiente y de velar por el uso racional de los recursos naturales, reforzándolo con en el inciso ( $\mathrm{j}$ ) del artículo 90, dentro del propio título, dedicado a los deberes ciudadanos, en cuanto a la protección los recursos naturales, la flora y la fauna y velar por la conservación de un medio ambiente sano. En el propio artículo se manejan los elementos a ser reconocidos y protegidos por el Estado dada su vinculación con el ambiente entre estos: desarrollo económico social sostenible, vida humana racional, así como: la supervivencia, el bienestar y la seguridad de las generaciones actuales y futuras.

En cuanto a los presupuestos doctrinales que configuran el contenido esencial de este derecho recordemos que en el primer capítulo del trabajo se había referido a este particular y tal caso cabría preguntarse si dichos presupuestos se corresponden con las establecidas por el legislador constitucional en la dogmática del artículo 75. El primer presupuesto del contenido esencial del derecho a un ambiente sano y equilibrado está referido la necesidad de preservar la vida individual en un entorno adecuado, pensamos está perfectamente delimitada en la preceptiva del artículo 75, cuando reconoce la estrecha vinculación con el desarrollo económico y social sostenible para hacer más racional la vida humana, cuando se habla de sostenibilidad aquí sin dudas se está hablando de calidad de vida y de un entorno adecuado. En cuanto a segundo presupuesto o dimensión de dicho derecho está referido al "derecho de la especie a subsistir en las generaciones futuras en un entorno adecuado", presupuesto que igualmente se encuentra de forma explícita en la preceptiva del artículo 75, cuando en una de sus partes se refiere a hacer más racional la vida humana y asegurar, la supervivencia, el bienestar y la seguridad de las generaciones actuales y futuras.

Máxime si a continuación se realiza un análisis de la Constitucionalización del derecho a un ambiente sano y ecológicamente equilibrado, en aras de determinar las eficiencias que presenta en función de proponer determinados presupuestos que contribuyan al perfeccionamiento de las vías procesales para su tutela judicial efectiva. 


\section{DE LA CONSTITUCIONALIZACIÓN DEL DERECHO A UN AMBIENTE SANO Y EQUILIBRADO, A LA NECESIDAD DEL PERFECCIONAMIEN- TO PLENA DE LAS VÍAS PROCESALES PARA SU TUTELA JUDICIAL EFECTIVA}

Como ya hemos visto el derecho a un ambiente sano y equilibrado, exige, al igual que los demás derechos humanos, para su efectiva protección y respeto, la existencia de mecanismos garantistas que puedan proteger al ciudadano tanto de actos o acciones abusivas provenientes de los funcionarios del Estado, como de individuos particulares y de grupos. En todo caso interesa ahora precisar si dentro del sistema de garantías generales previstas en el ordenamiento jurídico interno para los derechos del ciudadano se puede hablar de la existencia de garantías generales o específicas para el ejercicio del derecho a un ambiente sano.

Como se sabe la doctrina establece que la primera garantía es el reconocimiento del derecho, pero también se ha demostrado que el solo reconocimiento de los derechos no resuelve el tema de su pleno y efectivo disfrute. El esfuerzo tiene que centrarse en las garantías, es decir en aquellos mecanismos y medios para hacer efectivos estos derechos, en los instrumentos para asegurar su ejercicio y protegerlos. De esta forma las garantías de los derechos humanos pasan a convertirse en un elemento imprescindible para hacer efectivo el momento que media desde el reconocimiento de los derechos hasta su real eficacia jurídica en las relaciones humanas, de ahí que se establezca en los textos constitucionales una relación simbiótica entre derechos y garantías, al consagrar no sólo los derechos sino también sus mecanismos protectores que adquieren hoy una gran diversidad comprendiendo tanto los tradicionales medios jurisdiccionales hasta las vías extrajudiciales y las llamadas garantías normativas.

Como se conoce siendo el derecho a un ambiente sano un derecho de tercera generación, ubicado por tanto temporalmente su reconocimiento en la década de los 70 y 80 del pasado, dándose como hemos visto los primeros pasos para su reconocimiento con el texto constitucional cubano de 1976, en cual tampoco establecía una regulación precisa en relación con los mecanismos de garantías, pues el Capítulo VII dedicado al catálogo de derechos y sus garantías aun cuando en su título rezaba "Derechos, Deberes y Garantías Fundamentales", más bien se positivaron las condiciones materiales imprescindibles para la realización de los mismos, no así con las vías dirigidas a la defensa jurídica de los derechos.

No obstante, dispersos en el texto constitucional de 1976 se regulan algunas vías o mecanismos que de algún modo servían para la protección de los derechos, los cuales podíamos considerar dentro de la clasificación ya apuntada con anterioridad en cuanto a vías jurisdiccionales, no jurisdiccionales y las denominadas garantías abstractas o normativas que pueden activarse en el supuesto de vulneración de los derechos fundamentales. 
Siendo el caso de que en el ordenamiento jurídico cubano el empleo de los mecanismos jurisdiccionales para la protección de los derechos humanos hasta la llegada de la Constitución de 2019 encontrábamos serias limitaciones en tanto no existían procedimientos jurisdiccionales concentrados y expeditos dirigidos a la tutela jurídica de los derechos humanos y en todo caso la legislación ordinaria vigente hasta el presente fija a los tribunales entre sus principales objetivos: amparar la vida, la libertad, la dignidad, el honor, el patrimonio, las relaciones familiares y los demás derechos e intereses legítimos de los ciudadanos ${ }^{12}$. Sin embargo, a los tribunales les han quedado reservados únicamente las cuestiones de legalidad, no existiendo la jurisdicción constitucional, al quedar reducido el subsistema de garantías jurisdiccionales a las llamadas garantías generales o medios procesales ordinarios, o sea, los procedimientos ordinarios o comunes (Civil, Penal, Laboral, Administrativo) a través de los cuales se protegen los derechos de carácter ordinario y solo de forma refleja o indirecta pueden utilizarse para la tutela de los derechos humanos.

En relación con las garantías no jurisdiccionales, en el ordenamiento jurídico se concretan en la queja ante la Fiscalía General de la República o sus dependencias territoriales y la queja administrativa. Su fundamento constitucional radicaba en el artículo 63 de la Constitución, si bien este no agotaba toda la dimensión constitucional del derecho de queja y petición, entre otras cuestiones porque la reserva legal implícita en este artículo de la Constitución de 1976 nunca logró desarrollo constitucional.

En cuanto a las garantías normativas o abstractas, considerando como tales aquellas instituciones comprendidas en la Constitución destinadas a enfrentar preventivamente las presuntas violaciones de los derechos fundamentales por parte de los órganos estatales, se puede apreciar que, en el texto fundamental de 1976 para el caso del derecho a un ambiente sano, sólo se prevé la rigidez constitucional expuesta en el artículo 137 segundo párrafo. Prevista para todos los derechos constitucionalmente reconocidos. También dentro de este tipo de garantía encontramos la reserva legal considerada por algunos tratadistas como la primera y más importante garantía de los derechos que se enumera en una Constitución, esta garantía se encuentra establecida en nuestro texto constitucional, y significa que una vez consagrado un derecho en la constitución, el límite, la restricción a ese derecho solo debe quedar establecida por ley formal emanada del órgano legislativo.

Otras vías empleadas tradicionalmente en nuestro país como forma de obtener un amparo extrajudicial ante presuntas violaciones a los derechos fundamentales por parte de los ciudadanos son el establecimiento de quejas y peticiones ante las instancias de los Órganos del Poder Popular, del Partido Comunista de Cuba y del resto de las organizaciones políticas, sociales y de masas reconocidas en el país, relacionado con la confianza y estima que tiene la población en dichas instancias. Estas se han encargado de solucionar las situaciones presentadas en ocasiones, pero puede afirmarse que sus resoluciones y decisiones no tienen fuerza vinculante ya que carecen de jurisdicción, por lo que la obligatoriedad de su cumplimiento más bien se torna en persuasión, sin menoscabo de que contribuyen adecuadamente como vías alternativas en la protección de los derechos fundamentales.

12. Vid. artículo 4 c Ley No 82 de 11 de julio de 1997 "Ley de los Tribunales Populares". 
En los últimos años también se ha hecho evidente que la población, en la reclamación de sus derechos, acude con una progresiva frecuencia a los órganos nacionales y territoriales de prensa, cual vía que ha ido ganando "legitimidad popular" en la solución de los conflictos derivados del incumplimiento o violación de un derecho. Esta vía también está imbricada de las desventajas anteriormente enunciadas para las otras garantías extrajurídicas.

Como se podrá comprender las vías anteriormente explicadas para la tutela de los derechos humanos en Cuba, con las dificultades ya apuntadas, son y siguen siendo las existentes hasta la promulgación el pasado 10 de abril de la Constitución de 2019. Con la promulgación de la Constitución cubana de 2019, pudiéramos afirmar sin temor a equivocaremos que se abre un nuevo capítulo en el tema de la tutela de los derechos humanos en nuestro país. Coincidimos de que una de las transformaciones conceptuales más importantes que ha sufrido el derecho cubano en materia de derechos humanos con la Constitución de 2019, fue la de consagrar un Título V, dedicado a los Derechos, Deberes y Garantías, en el cual además del reconocimiento de uno de los más amplios catálogo de derechos del mundo ${ }^{13}$, de las garantías materiales para su eficaz ejercicio, se instituyen por primera vez en nuestra Constitución socialista un conjunto de instrumentos jurídicos para la tutela jurídica de dichos derecho humanos.

Con la nueva Constitución cubana se dotó al ciudadano de herramientas de probada eficacia para garantizar el cumplimiento de sus derechos humanos, tanto individuales como colectivos; en tal sentido nos referiremos a solo tres de ellas por acercarse de algún modo las herramientas posibles para la defensa de los derechos colectivos, es el caso del artículo 92, en el cual se dispone que el Estado garantiza, de conformidad con la ley, que las personas puedan acceder a los órganos judiciales a fin de obtener una tutela efectiva de sus derechos e intereses legítimos. Definir lo que se entiende por tutela judicial efectiva, implica referir al derecho de toda persona de acceder a los tribunales en busca de Justicia, de acuerdo a lo que fue proclamado en el artículo 25 de la Declaración Universal de Derechos Humanos de 1948 en los términos siguientes:

“Toda persona tiene derecho a un recurso sencillo y rápido o a cualquier otro recurso efectivo ante los jueces o tribunales competentes, que la ampare contra actos que violen sus derechos fundamentales reconocidos por la Constitución, la ley o la presente convención, aun cuando tal violación sea cometida por personas que actúan en ejercicio de sus funciones oficiales."

En cuanto al alcance del derecho a la tutela judicial efectiva, se debe decir que el contenido del derecho a la tutela judicial efectiva es muy amplio, ya que se requiere para su observación no sólo al acceder a la justicia, sino también, durante el desarrollo del proceso y finalmente, al tiempo de ejecutarse la sentencia.

13. Incluido el derecho a un ambiente sano. 
Del mismo artículo 98 del nuevo texto constitucional dispone que toda persona que sufriere daño o perjuicio causado indebidamente por directivos, funcionarios y empleados del Estado con motivo del ejercicio de las funciones propias de sus cargos, tiene derecho a reclamar y obtener la correspondiente reparación o indemnización en la forma que establece la ley, sin dudas la posibilidad que los ciudadanos puedan acceder a un procedimiento para la reclamación, reparación e indemnización por daños y perjuicios ocasionados indebidamente por directivos, funcionarios y empleados del Estado, constituye otra herramienta de singular efectividad en la defensa de los derechos humanos, presente a la mayoría de las cartas magnas y ordenamiento jurídicos del mundo y por último el artículo 99 que se pronuncia en cuanto a que la persona a la que se le vulneren los derechos consagrados en la Constitución y, como consecuencia sufriere daño o perjuicio por órganos del Estado, sus directivos, funcionarios o empleados, con motivo de la acción u omisión indebida de sus funciones, así como por particulares o por entes no estatales, tiene derecho a reclamar ante los tribunales la restitución de los derechos y obtener, de conformidad con la ley, la correspondiente reparación o indemnización.

La ley establece aquellos derechos amparados por esta garantía, y el procedimiento preferente, expedito y concentrado para su cumplimiento. Es decir, en este caso se abre la posibilidad de que los ciudadanos puedan acudir a la vía jurisdiccional para la defensa de sus derechos al considerar que estos de alguna forma le han sido vulnerados, que como ya se conoce es la garantía más eficaz en tanto goza del beneficio de una sentencia con carácter vinculante. Sin duda alguna los tres instrumentos proclamados constitucionalmente constituyen mecanismos de una importancia decisiva en la defensa de los derechos humanos, sin embargo, en el caso de los derechos de tercera generación, como es el caso del derecho a un ambiente sano, estos instrumentos no son suficientes.

Lo anterior se explica por ello ya señalado en cuanto la naturaleza y esencia del derecho a un ambiente sano y ecológicamente equilibrado al encontramos frente un derecho con características especiales que lo distinguen del resto de las anteriores generaciones de derechos, e incluso presenta significativa connotación aun dentro de aquellos derechos que clasifican dentro de los llamados de solidaridad o de la tercera generación.

Por tanto, coincidimos plenamente con un gran número de autores que proclaman la necesidad de implementar garantías especiales para un derecho que de alguna forma también lo es, sobre todo por la esencia del derecho tutelado, con implicaciones no solo para la vida y supervivencia de su titular supuestamente afectado, sino para la supervivencia de las futuras generaciones, e incluso -lo que resulta más dramático aún- para la supervivencia de todo el planeta con sus numerosas formas de vida. Por tanto, pensamos que en momentos en que recién se acaba de promulgar una nueva Constitución, catalogada por muchos como una Constitución garantista, pero cuyas normas requieren del desarrollo de leyes para su plena aplicación, sería un momento oportuno para que nuestra Asamblea Nacional se pronunciara por un conjunto de mecanismos procesales para la tutela efectiva del derecho a un ambiente sano y equilibrado, tomando por supuesto como referencia a aquellas instituciones y mecanismos implementados en años recientes principalmente por los países latinoamericanos, quienes son los que 
más han avanzado en este tema, como lo es sin duda el caso de Bolivia, Ecuador, Colombia, y Perú entre otros.

De ahí que se puedan determinar algunas regularidades en relación con el reconocimiento e instrumentación de mecanismos de garantías al derecho a un ambiente sano y equilibrado. En cuanto a las garantías encaminadas a la tutela judicial efectiva del derecho a un ambiente sano, lo cierto es que no se ha logrado aún instrumentar las vías adecuadas, no obstante existe consenso doctrinal de su necesidad y también en cuanto a que las vías o causes procesales tradicionales del derecho administrativo, civil o penal empleadas no resuelven de manera íntegra su defensa, existiendo de hecho numerosas propuestas y proyectos legislativos con soluciones novedosas, algunas de las cuales van desde la creación de códigos ambientales que incluyen nuevas instituciones procesales o modifican el sentido de las clásicas, la instrumentación de jurisdicciones o instancias especiales.

De lo investigado a lo largo del trabajo fueron identificadas un conjunto de irregularidades que propenden a un cambio en la legislativa procesal ambiental actual y que se considera deben ser tenidas en cuenta por el sistema jurídico cubano, entre las que señalan las siguientes:

* En el ordenamiento jurídico cubano el empleo de los mecanismos jurisdiccionales para la protección de los derechos humanos hasta la llegada de la Constitución de 2019 encontrábamos serias limitaciones en tanto no existían procedimientos jurisdiccionales concentrados y expeditos dirigidos a la tutela jurídica de los derechos humanos y en todo caso la legislación ordinaria vigente hasta el presente fija a los tribunales entre sus principales objetivos: amparar la vida, la libertad, la dignidad, el honor, el patrimonio, las relaciones familiares y los demás derechos e intereses legítimos de los ciudadanos ${ }^{14}$.

* Sin embargo, a los tribunales les han quedado reservados únicamente las cuestiones de legalidad, no existiendo la jurisdicción constitucional, al quedar reducido el subsistema de garantías jurisdiccionales a las llamadas garantías generales o medios procesales ordinarios, o sea, los procedimientos ordinarios o comunes (Civil, Penal, Laboral, Administrativo) a través de los cuales se protegen los derechos de carácter ordinario y solo de forma refleja o indirecta pueden utilizarse para la tutela de los derechos humanos.

* Omisión de acciones populares como mecanismos de excelencia para la protección de los derechos e intereses colectivos entre ellos "el derecho a un ambiente sano"; su finalidad es proteger a la comunidad en su conjunto y respecto a sus derechos e intereses colectivos.

* Que la acción popular pueda ser interpuestas por cualquier persona a nombre de su comunidad, no es necesario demostrar la existencia de un daño o perjuicio, se persigue con ella que el juez ordene hacer o no hacer algo o que exija, tanto la realización de conductas necesarias para volver las cosas al estado anterior.

14. Vid. artículo 4 c Ley No 82 de 11 de julio de 1997 Ley de los Tribunales Populares. 
* Que se le atribuyan amplias facultades y legitimación al Ministerio Fiscal para defender los intereses difusos derivados de los daños al ambiente, que no es otra cosa que la defensa del derecho a un ambiente sano y ecológicamente equilibrado.

* Inexistencia de jueces especializados en materia de procesos ambientales en el sistema jurídico patrio.

* En relación con las garantías no jurisdiccionales, en el ordenamiento jurídico se concretan en la queja ante la Fiscalía General de la República o sus dependencias territoriales y la queja administrativa. Su fundamento constitucional radica en el actual artículo 61 de la Constitución, si bien este no agota toda la dimensión constitucional del derecho de queja y petición, entre otras cuestiones porque la reserva legal implícita en este artículo se encuentra pendiente de desarrollo legal.

* Ausencia de una ley o Código Procesal en materia ambiental y de una jurisdicción en dicha materia.

Ahora bien, en tanto el sistema jurídico cubano, aún no está lo suficientemente desarrollado en lo que respecta las concepciones teóricas y prácticas sobre la tutela efectiva, la investigación efectuada, evidencia la necesidad del perfeccionamiento de las normas y procedimientos encaminados a lograr la misma, frente a los fundamentos del Derecho Ciudadano a un Ambiente Sano y Ecológicamente Equilibrado, proponemos los siguientes presupuestos teóricos y normativos de manera que contribuyan al perfeccionamiento de la tutela judicial efectiva de este derecho en el ordenamiento jurídico cubano.

* Que la norma constitucional referida al reconocimiento y defensa de los derechos humanos que incluye el derecho a un ambiente sano y ecológicamente se implemente como norma de eficacia directa.

* Proponemos la unificación de la legislación referente al derecho ambiental en un Código Procesal Ambiental Único, que prevea mecanismos de acceso ágil y desprovisto de formalidades burocráticas al ciudadano de manera individual o en representación de intereses colectivos en la obtención de la tutela judicial efectiva.

* Que dicha norma tenga en cuenta un conjunto de principios doctrinales ambientales y de implementación en el derecho comparado entre ellos: jurisdicción ambiental, jueces especializados, régimen especial de responsabilidad objetiva, procesos sumarios, entre otros.

* Ampliar las facultades del Ministerio Fiscal encaminadas a la defensa del derecho a un ambiente sano y ecológicamente equilibrado, desde la perspectiva de que sus pronunciamientos sobre la protección al ciudadano, sean más materializables en la práctica jurídica.

* Que se especialicen los jueces y demás funcionarios que intervienen en los procesos ambientales.

* Que los casos de contaminaciones y daños al ambiente se ventilen en proceso sumario atendiendo 
a razones de tiempo y urgencia, ya que generalmente los daños al ambiente pueden ser progresivos, por lo que se necesita una tutela efectiva y sumaria y dejar la vía ordinaria para los casos más complejos.

* Que se empleen en ocasión de los procesos de tutela del derecho a un ambiente sano, entre otros las instituciones o principios siguientes:

- Inversión de la carga de la prueba o en otros casos teoría de las cargas dinámicas probatorias, considerándose que quien debe probar es aquella parte que se encuentre en mejores condiciones técnicas, económicas, jurídicas o fácticas, respecto de los hechos conducentes.

- La anticipación procesal de las pruebas y medidas cautelares, así como la llamada sentencia anticipada.

-La sentencia que se dicte en proceso referido a daño al ambiente, no cause estado de cosa juzgada.

* Que se cree una ley o Código Procesal en materia ambiental, así como de jurisdicciones en dicha materia.

\section{CONCLUSIONES}

PRIMERO: El Derecho a un Ambiente Sano y Equilibrado es un derecho de tercera generación o de solidaridad, que en su aspecto subjetivo está concebido como parte del ejercicio colectivo o difuso, posterior a los Pactos Internacionales de Derechos Humanos y es un derecho orientado a la cooperación y responsabilidad de la comunidad internacional, así como de la estructuración de un nuevo orden económico. Siendo manifestado su contenido esencial, a través de dos dimensiones que lo conforman: El derecho a preservar la vida individual en un entorno adecuado y el derecho de la especie a subsistir en las generaciones futuras en un entorno adecuado.

SEGUNDO: Que el proceso de constitucionalización del derecho a un ambiente sano y equilibrado en el país se ha producido de manera gradual en tres etapas, la primera con la promulgación de la Constitución de 1976, la segunda con la Reforma de 1992 y la tercera con la nueva Constitución de 2019, con la cual finalmente se produce la incorporación del derecho a un ambiente sano, como un derecho humano en el catálogo de derechos, constituyendo la premisa a partir de la cual en un futuro próximo deberán sistematizarse los presupuestos teóricos y normativos derivados de la dogmática particular del mismo; constituyendo a la vez, un referente para la necesaria coherencia y armonización del resto de las normas que deberán ordenar la actividad ambiental vigentes en el país a partir de las necesarias propuestas normativas para su cumplimiento más efectivo.

TERCERO: El sistema jurídico cubano, en cuanto al reconocimiento Derecho a un Ambiente Sano y Equilibrado, presenta una situación similar a los países latinoamericanos que más han avanzado en esta materia, por delante de muchos países europeos que aun reconocen este derecho de manera implícita asociado a otros derechos, sin embargo en el ámbito referido a los mecanismos procesales 
para la tutela, se debe avanzar en su instrumentación a partir de los causes que en esta materia propicia la nueva Constitución, con instituciones tales como la tutela judicial, el debido proceso y la vía jurisdiccional para la reclamación ante violaciones de los derechos humanos y teniendo como referente las experiencias logradas en esta materia de varios países de nuestra región y la propuesta de presupuestos teóricos y normativos formulados en esta investigación.

\section{RECOMENDACIONES}

En el orden legislativo:

A la Comisión de Asuntos Constitucionales y Jurídicos de la Asamblea Nacional del Poder Popular:

PRIMERA: Valorar la unificación de la legislación referente al derecho ambiental en un Código Procesal Ambiental Único, que prevea mecanismos de acceso ágil y desprovisto de formalidades burocráticas al ciudadano de manera individual o en representación de intereses colectivos en la obtención de la tutela judicial efectiva, y que además tenga en cuenta un conjunto de principios doctrinales ambientales y la implementación de mecanismos con buenos resultados en el derecho comparado entre ellos: jurisdicción ambiental, jueces especializados, régimen especial de responsabilidad objetiva, procesos sumarios, acciones de tutela, acciones populares, acciones de cumplimiento, entre otros

En el orden académico:

A la Dirección de legislación del Ministerio de Justicia, la Unión Nacional de Juristas de Cuba, al Sistema de Tribunales y al Departamento de Derecho de la Facultad de Ciencias Sociales y Humanísticas de la Universidad de Guantánamo:

SEGUNDA: Que se promueva y divulgue el estudio de temas referidos al Medio Ambiente, dada la importancia que reviste este fenómeno en la actualidad llevado a cabo mediante el proyecto de la Tarea Vida, a fin de que la población gane en cultura jurídica y se contribuya al perfeccionamiento de la tutela judicial efectiva de este derecho en el ordenamiento jurídico cubano interno.

TERCERA: Que la investigación sea utilizada como material actualizado y de amplio alcance doctrinal y exegético para las consultas de jueces, estudiantes y profesores, en aras de futuros trabajos relacionadas al tema, en cursos de pregrado en las Asignaturas de Derecho Constitucional, Derecho Procesal y Derecho Ambiental, y posgrados que se impartan de la materia por la Unión de Juristas y el Departamento de Derecho.

\section{REFERENCIAS}

- $\quad$ Bidart Campos, G. J. y Sandler, H. R. Estudios sobre la Reforma Constitucional de 1994. Buenos Aires: Ediciones Depalma, 1995.

- $\quad$ Bobbio, Norberto. Studi per una Teoria Generale del Diritto. Torino: Giappichelli, 1970. 
- Caraballo Maqueira, Leonel. "El pensamiento ambiental cubano”. Multimedia Derecho Ambiental Cubano. La Habana: 2006.

- Carmona Lara, María Luisa. Derechos en relación con el medio ambiente. México: UNAM, Instituto de investigaciones Jurídicas 2000. Acceso 29 de marzo de 2019 desde, Consultado en fecha 29 de marzo de 2019. http:// www.bibliojuridica.org/libros/libro.htm?l=66.

- Castillo Torres, Sergio Emilio "Reconocimiento y Garantías del Derecho a un Ambiente Sano y Ecológicamente Equilibrado en Cuba”. Tesis de Maestría. Universidad de Oriente, 2006.

- Carta de Derechos Ambientales y Obligaciones de Individuos, Grupos y Organizaciones, adoptada en Ginebra en 1991.

- Cutié Mustelier, Danelia. "El sistema de garantías de los Derechos Humanos en Cuba". Tesis de Doctor en Ciencias Jurídicas. Cuba: Santiago de Cuba, 1999.

- $\quad$ Constitución de la República de Cuba. 2019.

- Corte Constitucional, Sala plena de la Corte Constitucional. Expediente T-904. Sentencia SU-067 de 1993. Bogotá, 24 de febrero de 1993. Magistrados Ponentes: Fabio Morón Díaz y Ciro Angarita Barón.

- De Castro Cid, Benito. Los derechos económicos, sociales y culturales: análisis a la luz de la teoría general de los derechos humanos. España: Universidad de León, Secretariado de Publicaciones, León, 1993.

- Di Cagno, Victorio, “La Protección del Medio Ambiente en Cuba”. Edición provisional para la $V$ Conferencia Internacional sobre Medio Ambiente y Desarrollo. La Habana: Editorial de Ciencias Sociales, 2005.

- Decreto Ley No 200 De las Contravenciones en Materia de Medio Ambiente, de 22 de diciembre de 1999. Edición Dirección de Política Ambiental.

- Declaración Universal de los Derechos Humanos,1948

- $\quad$ Declaración de Estocolmo sobre Medio Humano, 16 de junio de 1972.

- Declaración de Nairobi sobre el Medio Ambiente, 18 de marzo de 1982.

- Declaración de Río de Janeiro en la Cumbre de la Tierra, 14 de junio de 1992.

- Fix-Zamudio, Héctor. La garantía jurisdiccional de la Constitución mexicana. Ensayo de una estructuración procesal del amparo. México: UNAM, Porrúa, Instituto de Investigaciones Jurídicas, IMDPC, 2015. 
- Londoño Toro Beatriz. "Algunas reflexiones sobre la exigibilidad de los derechos colectivos y del ambiente”. En Perspectivas del Derecho Ambiental en Colombia, 62. Bogotá: Editorial Universidad del Rosario, 2006.

- $\quad$ Ley No 82 de 11 de julio de 1997 Ley de los Tribunales Populares. Cuba.

- $\quad$ Ley Procedimiento civil, administrativo y Laboral, Ministerio de Justicia, La Habana, 2003. Cuba.

- Martín Mateo, Ramón. Manual de Derecho Ambiental. Segunda Edición Cerrada del 30 de abril de 1998. Madrid: Editorial TRIVIUM.

- Muñoz Guzmán, Marco Antonio. El medio ambiente sano como derecho humano. Disponible en Internet: Acceso 26 de abril de 2019, desde, http://www.scjn.gob.mx/Reforma/Foro/archivos/2743

- Prieto Valdés, Martha. "Garantías y defensa de los derechos fundamentales de la ciudadanía cubana”. en El otro Derecho, ILSA, Vol. 6, No. 2, Bogotá, (1994), 113-122.

- Rancol Borrero, Ivette. "Protección Jurídica Penal del Medio Ambiente en Cuba”. Trabajo de diploma presentado en opción al título de licenciada en Derecho. Universidad de Guantánamo, 2017.

- Vallenas Gaona, Jesús Rafael. El derecho a un ambiente sano y ecológicamente equilibrado. Acceso 30 de abril de 2020, desde, en http:// www.uv.es/ ripj/11vall2.htm

RECIBIDO: $16 / 09 / 2020$

APROBADO: 20/10/2020 


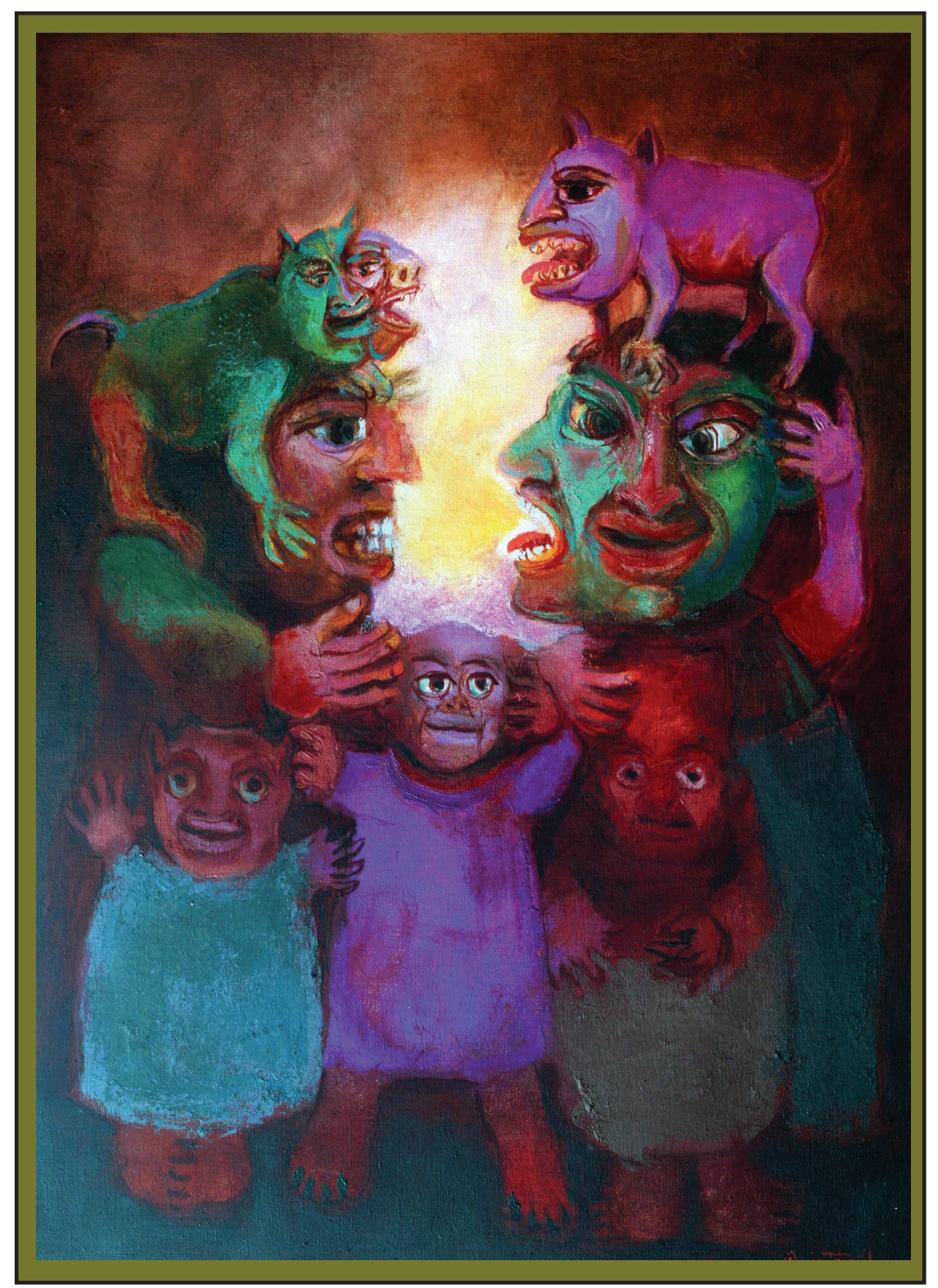

Titiriteros. Óleo, 2004. Artista plástico peruano, Alberto Quintanilla, (Cusco, 1934). 